\title{
Fixed Point Theory of Weak Contractions in Partially Ordered Metric Spaces
}

\author{
Chi-Ming Chen, ${ }^{1}$ Jin-Chirng Lee, ${ }^{2}$ and Chao-Hung Chen ${ }^{2}$ \\ ${ }^{1}$ Department of Applied Mathematics, National Hsinchu University of Education, No. 521, Nandah Road, Hsinchu City, Taiwan \\ ${ }^{2}$ Department of Applied Mathematics, Chung Yuan Christian University, Taiwan
}

Correspondence should be addressed to Chao-Hung Chen; chen@webmail.mlc.edu.tw

Received 12 March 2013; Accepted 20 April 2013

Academic Editor: Erdal Karapınar

Copyright (c) 2013 Chi-Ming Chen et al. This is an open access article distributed under the Creative Commons Attribution License, which permits unrestricted use, distribution, and reproduction in any medium, provided the original work is properly cited.

We prove two new fixed point theorems in the framework of partially ordered metric spaces. Our results generalize and improve many recent fixed point theorems in the literature.

\section{Introduction and Preliminaries}

Throughout this paper, by $\mathbb{R}^{+}$, we denote the set of all nonnegative real numbers, while $\mathbb{N}$ is the set of all natural numbers. Let $(X, d)$ be a metric space, $D$ a subset of $X$, and $f: D \rightarrow X$ a map. We say $f$ is contractive if there exists $\alpha \in[0,1)$ such that, for all $x, y \in D$,

$$
d(f x, f y) \leq \alpha \cdot d(x, y) .
$$

The well-known Banach's fixed point theorem asserts that if $D=X, f$ is contractive and $(X, d)$ is complete, then $f$ has a unique fixed point in $X$. In nonlinear analysis, the study of fixed points of given mappings satisfying certain contractive conditions in various abstract spaces has been investigated deeply. The Banach contraction principle [1] is one of the initial and crucial results in this direction. Also, this principle has many generalizations. For instance, Alber and Guerre-Delabriere in [2] suggested a generalization of the Banach contraction mapping principle by introducing the concept of weak contraction in Hilbert spaces. In [2], the authors also proved that the result of Eslamian and Abkar [3] is equivalent to the result of Dutta and Choudhury [4]. Later, weakly contractive mappings and mappings satisfying other weak contractive inequalities have been discussed in several works, some of which are noted in [4-16].

In 2008, Dutta and Choudhury proved the following theorem.
Theorem 1 (see $[4])$. Let $(X, d)$ be a complete metric space, and let $f: X \rightarrow X$ be such that

$$
\begin{array}{r}
\psi(d(f x, f y)) \leq \psi(d(x, y))-\phi(d(x, y)), \\
\text { for each } x, y \in X,
\end{array}
$$

where $\psi, \phi: \mathbb{R}^{+} \rightarrow \mathbb{R}^{+}$are continuous and nondecreasing, and $\psi(t)=\phi(t)=0$ if and only if $t=0$. Then $f$ has a fixed point in $X$.

Recently, Eslamian and Abkar [3] proved the following theorem.

Theorem 2 (see [3]). Let $(X, d)$ be a complete metric space, and let $f: X \rightarrow X$ be such that

$$
\begin{array}{r}
\psi(d(f x, f y)) \leq \alpha(d(x, y))-\beta(d(x, y)), \\
\text { for each } x, y \in X,
\end{array}
$$

where $\psi, \alpha, \beta: \mathbb{R}^{+} \rightarrow \mathbb{R}^{+}$are such that $\psi$ is continuous and nondecreasing, $\alpha$ is continuous, $\beta$ is lower semicontinuous, and

$$
\begin{array}{cll}
\psi(t)-\alpha(t)+\beta(t)>0 & \forall t>0, \\
\psi(t)=0 \quad \text { if and only if } t=0, & \alpha(0)=\beta(0)=0 .
\end{array}
$$

Then $f$ has a fixed point in $X$. 
In the recent, fixed point theory has developed rapidly in partially ordered metric spaces (e.g., [17-22]).

In 2012, Choudhury and Kundu [23] proved the following fixed point theorem as a generalization of Theorem 2 .

Theorem 3 (see [23]). Let $(X, \sqsubseteq)$ be a partially ordered set and suppose that there exists a metric $d$ in $X$ such that $(X, d)$ is a complete metric space and let $f: X \rightarrow X$ be a nondecreasing mapping such that

$$
\begin{array}{r}
\psi(d(f x, f y)) \leq \alpha(d(x, y))-\beta(d(x, y)), \\
\text { for each } x, y \in X \text { such that } x \sqsubseteq y,
\end{array}
$$

where $\psi, \alpha, \beta: \mathbb{R}^{+} \rightarrow \mathbb{R}^{+}$are such that $\psi$ is continuous and nondecreasing, $\alpha$ is continuous, $\beta$ is lower semicontinuous, and

$$
\begin{gathered}
\psi(t)-\alpha(t)+\beta(t)>0 \quad \forall t>0, \\
\psi(t)=0 \quad \text { if and only if } t=0, \quad \alpha(0)=\beta(0)=0 .
\end{gathered}
$$

Also, if any nondecreasing sequence $\left\{x_{n}\right\}$ in $X$ converges to $v$, then one assumes that

$$
x_{n} \sqsubseteq \nu \quad \forall n \in \mathbb{N} .
$$

If there exists $x_{0} \in X$ with $x_{0} \sqsubseteq f x_{0}$, then $f$ and $g$ have $a$ coincidence point in $X$.

In this paper, we prove two new fixed point theorems in the framework of partially ordered metric spaces. Our results generalize and improve many recent fixed point theorems in the literature.

\section{Fixed Point Results (I)}

We start with the following definition.

Definition 4. Let $(X, \sqsubseteq)$ be a partially ordered set and $f$ : $X \rightarrow X$. Then $f$ is said to be monotone nondecreasing if, for $x, y \in X$,

$$
x \sqsubseteq y \Longrightarrow f x \sqsubseteq f y .
$$

Let $(X, \sqsubseteq)$ be a partially ordered set. $x, y \in X$ are said to be comparable if either $x \sqsubseteq y$ or $y \sqsubseteq x$ holds.

In the section, we denote by $\Psi$ the class of functions $\psi$ : $\mathbb{R}^{+3} \rightarrow \mathbb{R}^{+}$satisfying the following conditions:

$\left(\psi_{1}\right) \psi$ is an increasing, continuous function in each coordinate;

$\left(\psi_{2}\right)$ for all $t \in \mathbb{R}^{+}, \psi(t, t, t) \leq t, \psi(0,0, t) \leq t$ and $\psi(t, 0,0) \leq t$.

Next, we denote by $\Phi$ the class of functions $\phi: \mathbb{R}^{+} \rightarrow \mathbb{R}^{+}$ satisfying the following conditions:

$\left(\phi_{1}\right) \phi$ is a continuous, nondecreasing function;

$\left(\phi_{2}\right) \phi(t)>0$ for $t>0$ and $\phi(0)=0$;

$\left(\phi_{3}\right) \phi$ is subadditive; that is, $\phi\left(t_{1}+t_{2}\right) \leq \phi\left(t_{1}\right)+\phi\left(t_{2}\right)$ for all $t_{1}, t_{2}>0$.
And we denote the following sets of functions:

$$
\Theta=\left\{\varphi: \mathbb{R}^{+} \rightarrow \mathbb{R}^{+} \text {such that } \varphi \text { is continuous }\right\},
$$

$\Xi=\left\{\xi: \mathbb{R}^{+} \rightarrow \mathbb{R}^{+}\right.$such that $\xi$ is lower continuous $\}$.

Let $X$ be a nonempty set, and let $(X, \sqsubseteq$ ) be a partially ordered set endowed with a metric $d$. Then, the triple $(X, \sqsubseteq, d)$ is called a partially ordered complete metric space.

We now state the main fixed point theorem for $(\varphi, \psi, \phi, \xi)$-contractions in partially ordered metric spaces, as follows.

Theorem 5. Let $(X, \sqsubseteq, d)$ be a partially ordered complete metric space. Let $f: X \rightarrow X$ be monotone nondecreasing, and

$$
\begin{aligned}
\varphi(d(f x, f y)) \leq & \psi(\phi(d(x, y)), \phi(d(x, f x)), \phi(d(y, f y))) \\
& -\xi(\max \{d(x, y), d(x, f x), d(y, f y)\}),
\end{aligned}
$$

for all comparable $x, y \in X$, where $\varphi \in \Theta, \psi \in \Psi, \phi \in \Phi$, and $\xi \in \Xi$, and

$$
\begin{gathered}
\varphi(t)-\phi(t)+\xi(t)>0 \quad \forall t>0, \\
\varphi(t)=0 \quad \text { if and only if } t=0, \quad \phi(0)=\xi(0)=0 .
\end{gathered}
$$

Suppose that either

(a) $f$ is continuous or

(b) if any nondecreasing sequence $\left\{x_{n}\right\}$ in $X$ converges to $v$, then one assumes that

$$
x_{n} \sqsubseteq \nu \quad \forall n \in \mathbb{N} .
$$

If there exists $x_{0} \in X$ with $x_{0} \sqsubseteq f x_{0}$, then $f$ has a fixed point in $X$.

Proof. Since $f$ is nondecreasing, by induction, we construct the sequence $\left\{x_{n}\right\}$ recursively as

$$
x_{n}=f^{n} x_{0}=f x_{n-1} \quad \forall n \in \mathbb{N} .
$$

Thus, we also conclude that

$$
x_{0} \sqsubset x_{1}=f x_{0} \sqsubseteq x_{2}=f x_{1} \sqsubseteq \cdots \sqsubseteq x_{n}=f x_{n-1} \sqsubseteq \cdots .
$$

If any two consecutive terms in (14) are equal, then the $f$ has a fixed point, and hence the proof is completed. So we may assume that

$$
d\left(x_{n-1}, x_{n}\right) \neq 0, \quad \forall n \in \mathbb{N} \text {. }
$$

Now, we claim that $d\left(x_{n}, x_{n+1}\right) \leq d\left(x_{n-1}, x_{n}\right)$ for all $n \in \mathbb{N}$. If not, we assume that $d\left(x_{n-1}, x_{n}\right)<d\left(x_{n}, x_{n+1}\right)$ for some $n \in \mathbb{N}$; 
substituting $x=x_{n}$ and $y=x_{n+1}$ in (10) and using the definition of the function $\psi$, we have

$$
\begin{aligned}
& \psi\left(\phi\left(d\left(x_{n}, x_{n+1}\right)\right), \phi\left(d\left(x_{n}, f x_{n}\right)\right), \phi\left(d\left(x_{n+1}, f x_{n+1}\right)\right)\right) \\
& \quad=\psi\left(\phi\left(d\left(x_{n}, x_{n+1}\right)\right), \phi\left(d\left(x_{n}, x_{n+1}\right)\right), \phi\left(d\left(x_{n+1}, x_{n+2}\right)\right)\right) \\
& \quad \leq \phi\left(d\left(x_{n+1}, x_{n+2}\right)\right), \\
& \xi\left(\max \left\{d\left(x_{n}, x_{n+1}\right), d\left(x_{n}, f x_{n}\right), d\left(x_{n+1}, f x_{n+1}\right)\right\}\right) \\
& \quad=\xi\left(\max \left\{d\left(x_{n}, x_{n+1}\right), d\left(x_{n}, x_{n+1}\right), d\left(x_{n+1}, x_{n+2}\right)\right\}\right) \\
& \quad=\xi\left(d\left(x_{n+1}, x_{n+2}\right)\right),
\end{aligned}
$$

and hence

$$
\begin{aligned}
\varphi(d & \left.\left(x_{n+1}, x_{n+2}\right)\right) \\
& =\varphi\left(d\left(f x_{n}, f x_{n+1}\right)\right) \\
& \leq \phi\left(d\left(x_{n+1}, x_{n+2}\right)\right)-\xi\left(d\left(x_{n+1}, x_{n+2}\right)\right) .
\end{aligned}
$$

Since $\varphi(t)-\phi(t)+\xi(t)>0$ for all $t>0$, we have that $d\left(x_{n+1}, x_{n+2}\right)=0$, which contradicts (15). Therefore, we conclude that

$$
d\left(x_{n}, x_{n+1}\right) \leq d\left(x_{n-1}, x_{n}\right) \quad \forall n \in \mathbb{N} .
$$

From the previous argument, we also have that for each $n \in \mathbb{N}$

$$
\varphi\left(d\left(x_{n}, x_{n+1}\right)\right) \leq \phi\left(d\left(x_{n-1}, x_{n}\right)\right)-\xi\left(d\left(x_{n-1}, x_{n}\right)\right) .
$$

It follows in (18) that the sequence $\left\{d\left(x_{n}, x_{n+1}\right)\right\}$ is monotone decreasing; it must converge to some $\eta \geq 0$. Taking limit as $n \rightarrow \infty$ in (19) and using the continuities of $\varphi$ and $\phi$ and the lower semicontinuous of $\xi$, we get

$$
\varphi(\eta) \leq \phi(\eta)-\xi(\eta)
$$

which implies that $\eta=0$. So we conclude that

$$
\lim _{n \rightarrow \infty} d\left(x_{n}, x_{n+1}\right)=0 \text {. }
$$

We next claim that $\left\{x_{n}\right\}$ is a Cauchy sequence; that is, for every $\varepsilon>0$, there exists $n \in \mathbb{N}$ such that if $p, q \geq n$, then $d\left(x_{p}, x_{q}\right)<\varepsilon$.

Suppose, on the contrary, that there exists $\epsilon>0$ such that, for any $n \in \mathbb{N}$, there are $p_{n}, q_{n} \in \mathbb{N}$ with $p_{n}>q_{n} \geq n$ satisfying

$$
d\left(x_{q_{n}}, x_{p_{n}}\right) \geq \epsilon
$$

Further, corresponding to $q_{n} \geq n$, we can choose $p_{n}$ in such a way that it the smallest integer with $p_{n}>q_{n} \geq n$ and $d\left(x_{q_{n}}, x_{p_{n}}\right) \geq \epsilon$. Therefore $d\left(x_{q_{n}}, x_{p_{n}-1}\right)<\epsilon$. Now we have that for all $n \in \mathbb{N}$

$$
\begin{aligned}
\epsilon & \leq d\left(x_{p_{n}}, x_{q_{n}}\right) \\
& \leq d\left(x_{p_{n}}, x_{p_{n}-1}\right)+d\left(x_{p_{n}-1}, x_{q_{n}}\right) \\
& <d\left(x_{p_{n}}, x_{p_{n}-1}\right)+\epsilon .
\end{aligned}
$$

By letting $n \rightarrow \infty$. we get that

$$
\lim _{n \rightarrow \infty} d\left(x_{p_{n}}, x_{q_{n}}\right)=\epsilon .
$$

On the other hand, we have

$$
\begin{aligned}
& d\left(x_{p_{n}}, x_{q_{n}}\right) \\
& \quad \leq d\left(x_{p_{n}}, x_{p_{n}-1}\right)+d\left(x_{p_{n}-1}, x_{q_{n}-1}\right)+d\left(x_{q_{n}-1}, x_{q_{n}}\right), \\
& d\left(x_{p_{n}-1}, x_{q_{n}-1}\right) \\
& \quad \leq d\left(x_{p_{n}-1}, x_{p_{n}}\right)+d\left(x_{p_{n}}, x_{q_{n}}\right)+d\left(x_{q_{n}}, x_{q_{n}-1}\right) .
\end{aligned}
$$

Letting $n \rightarrow \infty$, then we get

$$
\lim _{n \rightarrow \infty} d\left(x_{p_{n}-1}, x_{q_{n}-1}\right)=\epsilon
$$

By (14), we have that the elements $x_{p_{n}}$ and $x_{q_{n}}$ are comparable. Substituting $x=x_{p_{n}-1}$ and $y=x_{q_{n}-1}$ in (10), we have that, for all $n \in \mathbb{N}$,

$$
\begin{gathered}
\psi\left(\phi\left(d\left(x_{p_{n}-1}, x_{q_{n}-1}\right)\right), \phi\left(d\left(x_{p_{n}-1}, f x_{p_{n}-1}\right)\right),\right. \\
\left.\phi\left(d\left(x_{q_{n}-1}, f x_{q_{n}-1}\right)\right)\right) \\
\leq \psi\left(\phi\left(d\left(x_{p_{n}-1}, x_{q_{n}-1}\right)\right), \phi\left(d\left(x_{p_{n}-1}, x_{p_{n}}\right)\right),\right. \\
\left.\phi\left(d\left(x_{q_{n}-1}, x_{q_{n}}\right)\right)\right), \\
M\left(x_{p_{n}-1}, x_{q_{n}-1}\right) \\
=\max \left\{d\left(x_{p_{n}-1}, x_{q_{n}-1}\right), d\left(x_{p_{n}-1}, f x_{p_{n}-1}\right),\right. \\
\left.d\left(x_{q_{n}-1}, f x_{q_{n}-1}\right)\right\} \\
=\max \left\{d\left(x_{p_{n}-1}, x_{q_{n}-1}\right), d\left(x_{p_{n}-1}, x_{p_{n}}\right),\right. \\
\left.d\left(x_{q_{n}-1}, x_{q_{n}}\right)\right\} .
\end{gathered}
$$

By the previous argument and using inequality (10), we can conclude that

$$
\begin{aligned}
\varphi(\epsilon) & \leq \psi(\phi(\epsilon), 0,0)-\xi(\epsilon) \\
& \leq \phi(\epsilon)-\xi(\epsilon),
\end{aligned}
$$

which implies that $\epsilon=0$, a contradiction. Therefore, the sequence $\left\{x_{n}\right\}$ is a Cauchy sequence.

Since $X$ is complete, there exists $v \in X$ such that

$$
\lim _{n \rightarrow \infty} x_{n}=v
$$

Suppose that (a) holds. Then

$$
v=\lim _{n \rightarrow \infty} x_{n+1}=\lim _{n \rightarrow \infty} f x_{n}=f \nu .
$$

Thus, $v$ is a fixed point in $X$. 
Suppose that (b) holds; that is, $x_{n} \sqsubseteq \nu$ for all $n \in \mathbb{N}$. Substituting $x=x_{n}$ and $y=v$ in (10), we have that

$$
\begin{aligned}
\varphi( & \left.\left(x_{n+1}, f \nu\right)\right) \\
= & \varphi\left(d\left(f x_{n}, f \nu\right)\right) \\
\leq & \psi\left(\phi\left(d\left(x_{n}, \nu\right)\right), \phi\left(d\left(x_{n}, f x_{n}\right)\right), \phi(d(\nu, f v))\right) \\
& -\xi\left(\max \left\{d\left(x_{n}, \nu\right), d\left(x_{n}, f x_{n}\right), d(\nu, f v)\right\}\right) .
\end{aligned}
$$

Taking limit as $n \rightarrow \infty$ in equality (31), we have

$$
\begin{aligned}
\varphi(d(\nu, f \nu)) & \leq \psi(\phi(0), \phi(o), \phi(d(\nu, f \nu)))-\xi(d(\nu, f \nu)) \\
& \leq \phi(d(\nu, f \nu))-\xi(d(\nu, f \nu))
\end{aligned}
$$

which implies that $d(\nu, f \nu)=0$; that is $\nu=f \nu$. So we complete the proof.

If we let

$$
\begin{aligned}
\psi & (\phi(d(x, y)), \phi(d(x, f x)), \phi(d(y, f y))) \\
& =\max \{\phi(d(x, y)), \phi(d(x, f x)), \phi(d(y, f y))\},
\end{aligned}
$$

it is easy to get the following theorem.

Theorem 6. Let $(X, \sqsubseteq, d)$ be a partially ordered complete metric space. Let $f: X \rightarrow X$ be monotone nondecreasing, and

$$
\begin{aligned}
\varphi(d(f x, f y)) \\
\leq \max \{\phi(d(x, y)), \phi(d(x, f x)), \phi(d(y, f y))\} \\
\quad-\xi(\max \{d(x, y), d(x, f x), d(y, f y)\}),
\end{aligned}
$$

for all comparable $x, y \in X$, where $\varphi \in \Theta, \phi \in \Phi$, and $\xi \in \Xi$, and

$$
\begin{gathered}
\varphi(t)-\phi(t)+\xi(t)>0 \quad \forall t>0, \\
\varphi(t)=0 \quad \text { if and only if } t=0, \quad \phi(0)=\xi(0)=0 .
\end{gathered}
$$

Suppose that either

(a) $f$ is continuous or

(b) if any nondecreasing sequence $\left\{x_{n}\right\}$ in $X$ converges to $v$, then one assumes that

$$
x_{n} \sqsubseteq \nu \quad \forall n \in \mathbb{N} .
$$

If there exists $x_{0} \in X$ with $x_{0} \sqsubseteq f x_{0}$, then $f$ has a fixed point in $X$.

\section{Fixed Point Results (II)}

In the section, we denote by $\Psi$ the class of functions $\psi$ : $\mathbb{R}^{+3} \rightarrow \mathbb{R}^{+}$satisfying the following conditions:

$\left(\psi_{1}\right) \psi$ is an increasing and continuous function in each coordinate; $\left(\psi_{2}\right)$ for $t \in \mathbb{R}^{+}, \phi(t, t, t) \leq t, \phi(t, 0,0) \leq t$, and $\phi(0,0, t) \leq$ $t$.

Next, we denote by $\Theta$ the class of functions $\varphi: \mathbb{R}^{+} \rightarrow \mathbb{R}^{+}$ satisfying the following conditions:

$\left(\varphi_{1}\right) \varphi$ is continuous and nondecreasing;

$\left(\varphi_{2}\right)$ for $t>0, \varphi(t)>0$ and $\varphi(0)=0$.

And we denote by $\Phi$ the class of functions $\phi: \mathbb{R}^{+} \rightarrow \mathbb{R}^{+}$ satisfying the following conditions.

$\left(\phi_{1}\right) \phi$ is continuous;

$\left(\phi_{2}\right)$ for $t>0, \phi(t)>0$ and $\phi(0)=0$.

We now state the main fixed point theorem for the $(\psi, \varphi, \phi)$-contractions in partially ordered metric spaces, as follows.

Theorem 7. Let $(X, \sqsubseteq, d)$ be a partially ordered complete metric space, and let $f: X \rightarrow X$ be monotone nondecreasing, and

$$
\begin{aligned}
\varphi(d(f x, f y)) \\
\leq \psi(\varphi(d(x, y)), \varphi(d(x, f x)), \varphi(d(y, f y))) \\
\quad-\phi(M(x, y))+L \cdot m(x, y),
\end{aligned}
$$

for all comparable $x, y \in X$ and $\psi \in \Psi, \varphi \in \Theta, \phi \in \Phi$, where $L>0$ and

$$
\begin{aligned}
& M(x, y)=\max \{d(x, y), d(x, f x), d(y, f y)\}, \\
& m(x, y) \\
& =\min \{d(x, y), d(x, f x), d(y, f y), d(x, f y), \\
& d(y, f x)\} .
\end{aligned}
$$

Suppose that either

(a) $f$ is continuous or

(b) if any nondecreasing sequence $\left\{x_{n}\right\}$ in $X$ converges to $v$, then one assumes that

$$
x_{n} \sqsubseteq \nu \quad \forall n \in \mathbb{N} .
$$

If there exists $x_{0} \in X$ with $x_{0} \sqsubseteq f x_{0}$, then $f$ has a fixed point in $X$.

Proof. If $f x_{0}=x_{0}$, then the proof is finished. Suppose that $x_{0} \sqsubset f x_{0}$. Since $f$ is nondecreasing, by induction, we construct the sequence $\left\{x_{n}\right\}$ recursively as

$$
x_{n}=f^{n} x_{0}=f x_{n-1} \quad \forall n \in \mathbb{N} .
$$

Thus, we also conclude that

$$
x_{0} \sqsubset x_{1}=f x_{0} \sqsubseteq x_{2}=f x_{1} \sqsubseteq \cdots \sqsubseteq x_{n}=f x_{n-1} \sqsubseteq \cdots .
$$

We now claim that

$$
\lim _{n \rightarrow \infty} d\left(x_{n}, x_{n+1}\right)=0 .
$$


Put $x=x_{n-1}$ and $y=x_{n}$ in (37). Note that

$$
\begin{aligned}
& m\left(x_{n-1}, x_{n}\right) \\
& =\min \left\{d\left(x_{n-1}, x_{n}\right), d\left(x_{n-1}, f x_{n-1}\right),\right. \\
& \left.\quad d\left(x_{n}, f x_{n}\right), d\left(x_{n-1}, f x_{n}\right), d\left(x_{n}, f x_{n-1}\right)\right\} \\
& =\min \left\{d\left(x_{n-1}, x_{n}\right), d\left(x_{n-1}, x_{n}\right), d\left(x_{n}, x_{n+1}\right),\right. \\
& \left.\quad d\left(x_{n-1}, x_{n+1}\right), d\left(x_{n}, x_{n}\right)\right\} \\
& =0 .
\end{aligned}
$$

So, we obtain that

$$
\begin{aligned}
& \varphi\left(d\left(x_{n}, x_{n+1}\right)\right) \\
& =\varphi\left(d\left(f x_{n-1}, f x_{n}\right)\right) \\
& \leq \psi\left(\varphi\left(d\left(x_{n-1}, x_{n}\right)\right), \varphi\left(d\left(x_{n-1}, f x_{n-1}\right)\right),\right. \\
& \left.\quad \varphi\left(d\left(x_{n}, f x_{n}\right)\right)\right)-\phi\left(M\left(x_{n-1}, x_{n}\right)\right) \\
& \leq \psi\left(\varphi\left(d\left(x_{n-1}, x_{n}\right)\right), \varphi\left(d\left(x_{n-1}, x_{n}\right)\right), \varphi\left(d\left(x_{n}, x_{n+1}\right)\right)\right) \\
& \quad-\phi\left(M\left(x_{n-1}, x_{n}\right)\right),
\end{aligned}
$$

where

$$
\begin{aligned}
M & \left(x_{n-1}, x_{n}\right) \\
& =\max \left\{d\left(x_{n-1}, x_{n}\right), d\left(x_{n-1}, f x_{n-1}\right), d\left(x_{n}, f x_{n}\right)\right\} \\
& =\max \left\{d\left(x_{n-1}, x_{n}\right), d\left(x_{n-1}, x_{n}\right), d\left(x_{n}, x_{n+1}\right)\right\} .
\end{aligned}
$$

We now claim that

$$
d\left(x_{n}, x_{n+1}\right)<d\left(x_{n-1}, x_{n}\right), \quad \forall n \in \mathbb{N} .
$$

If not, we assume that $d\left(x_{n-1}, x_{n}\right) \leq d\left(x_{n}, x_{n+1}\right)$; then $\varphi\left(d\left(x_{n-1}, x_{n}\right)\right) \leq \varphi\left(d\left(x_{n}, x_{n+1}\right)\right)$, since $\varphi$ is non-decreasing. Using inequality (44) and the conditions of the function $\psi$, we have that, for each $n \in \mathbb{N}$,

$$
\varphi\left(d\left(x_{n}, x_{n+1}\right)\right) \leq \varphi\left(d\left(x_{n}, x_{n+1}\right)\right)-\phi\left(d\left(x_{n}, x_{n+1}\right)\right),
$$

which implies that $\phi\left(d\left(x_{n}, x_{n+1}\right)\right)=0$, and hence $d\left(x_{n}, x_{n+1}\right)=$ 0 . This contradicts our initial assumption.

From the previous argument, we have that, for each $n \in \mathbb{N}$,

$$
\begin{gathered}
\varphi\left(d\left(x_{n}, x_{n+1}\right)\right) \leq \varphi\left(d\left(x_{n-1}, x_{n}\right)\right)-\phi\left(d\left(x_{n-1}, x_{n}\right)\right), \\
d\left(x_{n}, x_{n+1}\right)<d\left(x_{n-1}, x_{n}\right) .
\end{gathered}
$$

And since the sequence $\left\{d\left(x_{n}, x_{n+1}\right)\right\}$ is decreasing, it must converge to some $\eta \geq 0$. Taking limit as $n \rightarrow \infty$ in (48) and by the continuity of $\varphi$ and $\phi$, we get

$$
\varphi(\eta) \leq \varphi(\eta)-\phi(\eta)
$$

and so we conclude that $\phi(\eta)=0$ and $\eta=0$.

We next claim that $\left\{x_{n}\right\}$ is Cauchy; that is, for every $\varepsilon>0$, there exists $n \in \mathbb{N}$ such that if $p, q \geq n$, then $d\left(x_{p}, x_{q}\right)<\varepsilon$.
Suppose, on the contrary, that there exists $\epsilon>0$ such that, for any $n \in \mathbb{N}$, there are $p_{n}, q_{n} \in \mathbb{N}$ with $p_{n}>q_{n} \geq n$ satisfying

$$
d\left(x_{q_{n}}, x_{p_{n}}\right) \geq \epsilon
$$

Further, corresponding to $q_{n} \geq n$, we can choose $p_{n}$ in such a way that it the smallest integer with $p_{n}>q_{n} \geq n$ and $d\left(x_{q_{n}}, x_{p_{n}}\right) \geq \epsilon$. Therefore $d\left(x_{q_{n}}, x_{p_{n}-1}\right)<\epsilon$. By the rectangular inequality, we have

$$
\begin{aligned}
\epsilon & \leq d\left(x_{p_{n}}, x_{q_{n}}\right) \\
& \leq d\left(x_{p_{n}}, x_{p_{n}-1}\right)+d\left(x_{p_{n}-1}, x_{q_{n}}\right) \\
& <d\left(x_{p_{n}}, x_{p_{n}-1}\right)+\epsilon .
\end{aligned}
$$

Letting $n \rightarrow \infty$, then we get

$$
\lim _{n \rightarrow \infty} d\left(x_{p_{n}}, x_{q_{n}}\right)=\epsilon
$$

On the other hand, we have

$$
\begin{aligned}
& d\left(x_{p_{n}}, x_{q_{n}}\right) \\
& \quad \leq d\left(x_{p_{n}}, x_{p_{n}-1}\right)+d\left(x_{p_{n}-1}, x_{q_{n}-1}\right)+d\left(x_{q_{n}-1}, x_{q_{n}}\right), \\
& d\left(x_{p_{n}-1}, x_{q_{n}-1}\right) \\
& \quad \leq d\left(x_{p_{n}-1}, x_{p_{n}}\right)+d\left(x_{p_{n}}, x_{q_{n}}\right)+d\left(x_{q_{n}}, x_{q_{n}-1}\right) .
\end{aligned}
$$

By letting $n \rightarrow \infty$, we get that

$$
\lim _{n \rightarrow \infty} d\left(x_{p_{n}-1}, x_{q_{n}-1}\right)=\epsilon
$$

Using inequalities (37), (52), and (54) and putting $x=x_{p_{n}-1}$ and $y=x_{q_{n}-1}$, we have that

$$
\begin{gathered}
\varphi\left(d\left(x_{p_{n}}, x_{q_{n}}\right)\right) \\
=\varphi\left(d\left(f x_{p_{n}-1}, f x_{q_{n}-1}\right)\right) \\
\leq \psi\left(\varphi\left(d\left(x_{p_{n}-1}, x_{q_{n}-1}\right)\right), \varphi\left(d\left(x_{p_{n}-1}, f x_{p_{n}-1}\right)\right),\right. \\
\left.\varphi\left(d\left(x_{q_{n}-1}, f x_{q_{n}-1}\right)\right)\right) \\
-\phi\left(M\left(x_{p_{n}-1}, x_{q_{n}-1}\right)\right)+L \cdot m\left(x_{p_{n}-1}, x_{q_{n}-1}\right) \\
=\psi\left(\varphi\left(d\left(x_{p_{n}-1}, x_{q_{n}-1}\right)\right), \varphi\left(d\left(x_{p_{n}-1}, x_{p_{n}}\right)\right),\right. \\
\left.\varphi\left(d\left(x_{q_{n}-1}, x_{q_{n}}\right)\right)\right) \\
-\phi\left(M\left(x_{p_{n}-1}, x_{q_{n}-1}\right)\right)+L \cdot m\left(x_{p_{n}-1}, x_{q_{n}-1}\right),
\end{gathered}
$$


where

$$
\begin{aligned}
& M\left(x_{p_{n}-1}, x_{q_{n}-1}\right) \\
& =\max \left\{d\left(x_{p_{n}-1}, x_{q_{n}-1}\right), d\left(x_{p_{n}-1}, x_{p_{n}}\right), d\left(x_{q_{n}-1}, x_{q_{n}}\right)\right\}, \\
& m\left(x_{p_{n}-1}, x_{q_{n}-1}\right) \\
& =\min \left\{d\left(x_{p_{n}-1}, x_{q_{n}-1}\right), d\left(x_{p_{n}-1}, x_{p_{n}}\right),\right. \\
& \left.d\left(x_{q_{n}-1}, x_{q_{n}}\right), d\left(x_{p_{n}-1}, x_{q_{n}}\right), d\left(x_{q_{n}-1}, x_{p_{n}}\right)\right\} .
\end{aligned}
$$

Letting $n \rightarrow \infty$, then we obtain that

$$
\begin{gathered}
\lim _{n \rightarrow \infty} M\left(x_{p_{n}-1}, x_{q_{n}-1}\right)=\epsilon, \\
\lim _{n \rightarrow \infty} m\left(x_{p_{n}-1}, x_{q_{n}-1}\right)=0, \\
\varphi(\epsilon) \leq \psi(\varphi(\epsilon), 0,0)-\phi(\epsilon) \leq \varphi(\epsilon)-\phi(\epsilon) .
\end{gathered}
$$

This implies that $\phi(\epsilon)=0$, and hence $\epsilon=0$. So we get a contraction. Therefore $\left\{x_{n}\right\}$ is a Cauchy sequence.

Since $X$ is complete, there exists $v \in X$ such that

$$
\lim _{n \rightarrow \infty} x_{n}=v
$$

Suppose that (a) holds. Then

$$
v=\lim _{n \rightarrow \infty} x_{n+1}=\lim _{n \rightarrow \infty} f x_{n}=f v .
$$

Thus, $v$ is a fixed point in $X$

Suppose that (b) holds; that is, $x_{n} \sqsubseteq \nu$ for all $n \in \mathbb{N}$. Substituting $x=x_{n}$ and $y=v$ in (37), we have that

$$
\begin{aligned}
\varphi( & \left.\left(x_{n+1}, f \nu\right)\right) \\
= & \varphi\left(d\left(f x_{n}, f \nu\right)\right) \\
\leq & \psi\left(\varphi\left(d\left(x_{n}, v\right)\right), \varphi\left(d\left(x_{n}, f x_{n}\right)\right), \varphi(d(\nu, f v))\right) \\
& \quad-\phi\left(M\left(x_{n}, v\right)\right)+L \cdot m\left(x_{n}, v\right),
\end{aligned}
$$

where

$$
\begin{aligned}
& M\left(x_{n}, v\right)=\max \left\{d\left(x_{n}, v\right), d\left(x_{n}, f x_{n}\right), d(\nu, f v)\right\}, \\
& m\left(x_{n}, v\right) \\
& =\min \left\{d\left(x_{n}, v\right), d\left(x_{n}, f x_{n}\right), d(\nu, f v), d\left(x_{n}, f v\right)\right. \\
& \left.d\left(\nu, f x_{n}\right)\right\} .
\end{aligned}
$$

Letting $n \rightarrow \infty$, then we obtain that

$$
\begin{gathered}
M\left(x_{n}, \nu\right) \longrightarrow d(\nu, f v), \quad m\left(x_{n}, \nu\right) \longrightarrow 0, \\
\varphi(d(\nu, f v)) \leq \psi(\varphi(0), \varphi(0), \varphi(d(\nu, f v)))-\phi(d(\nu, f \nu)) \\
\leq \varphi(d(\nu, f v))-\phi(d(\nu, f v)),
\end{gathered}
$$

which implies that $d(\nu, f v)=0$; that is, $v=f \nu$. So we complete the proof.
If we let

$$
\begin{aligned}
& \psi(\varphi(d(x, y)), \varphi(d(x, f x)), \varphi(d(y, f y))) \\
& =\max \{\varphi(d(x, y)), \varphi(d(x, f x)), \varphi(d(y, f y))\},
\end{aligned}
$$

it is easy to get the following theorem.

Theorem 8. Let $(X, \sqsubseteq, d)$ be a partially ordered complete metric space, and let $f: X \rightarrow X$ be monotone nondecreasing, and

$$
\begin{aligned}
\varphi(d(f x, f y)) \\
\leq \max \{\varphi(d(x, y)), \varphi(d(x, f x)), \varphi(d(y, f y))\} \\
\quad-\phi(M(x, y))+L \cdot m(x, y),
\end{aligned}
$$

for all comparable $x, y \in X$ and $\varphi \in \Theta, \phi \in \Phi$, where $L>0$ and

$$
\begin{gathered}
M(x, y)=\max \{d(x, y), d(x, f x), d(y, f y)\}, \\
m(x, y)=\min \{d(x, y), d(x, f x), d(y, f y), d(x, f y), \\
d(y, f x)\} .
\end{gathered}
$$

Suppose that either

(a) $f$ is continuous or

(b) if any nondecreasing sequence $\left\{x_{n}\right\}$ in $X$ converges to $v$, then one assumes that

$$
x_{n} \sqsubseteq \nu \quad \forall n \in \mathbb{N} .
$$

If there exists $x_{0} \in X$ with $x_{0} \sqsubseteq f x_{0}$, then $f$ has a fixed point in $X$.

\section{Acknowledgment}

The authors would like to thank the referee(s) for the many useful comments and suggestions for the improvement of the paper.

\section{References}

[1] S. Banach, "Sur les operations dans les ensembles abstraits et leur application aux equations integerales," Fundamenta Mathematicae, vol. 3, pp. 133-181, 1922.

[2] I. Ya. Alber and S. Guerre-Delabriere, "Principles of weakly contractive maps in Hilbert spaces," in New Results in Operator Theory, I. Gohberg and Yu. Lyubich, Eds., vol. 98 of Advances and Applications, pp. 7-22, Birkhauser, Basel, Switzerland, 1997.

[3] M. Eslamian and A. Abkar, "A fixed point theorem for generalized weakly contractive mappings in complete metric space," Italian Journal of Pure and Applied Mathematics. In press.

[4] P. N. Dutta and B. S. Choudhury, "A generalisation of contraction principle in metric spaces," Fixed Point Theory and Applications, vol. 2008, Article ID 406368, 8 pages, 2008.

[5] H. Aydi, E. Karapınar, and B. Samet, "Remarks on some recent fixed point theorems," Fixed Point Theory and Applications, vol. 2012, article 76, 2012. 
[6] H. Aydi, E. Karapınar, and W. Shatanawi, "Coupled fixed point results for $(\varphi, \psi)$-weakly contractive condition in ordered partial metric spaces," Computers \& Mathematics with Applications, vol. 62, no. 12, pp. 4449-4460, 2011.

[7] W.-S. Du, "On coincidence point and fixed point theorems for nonlinear multivalued maps," Topology and its Applications, vol. 159, no. 1, pp. 49-56, 2012.

[8] W.-S. Du, "On generalized weakly directional contractions and approximate fixed point property with applications," Fixed Point Theory and Applications, vol. 2012, article 6, 2012.

[9] W.-S. Du and S.-X. Zheng, "Nonlinear conditions for coincidence point and fixed point theorems," Taiwanese Journal of Mathematics, vol. 16, no. 3, pp. 857-868, 2012.

[10] W.-S. Du and S.-X. Zheng, "New nonlinear conditions and inequalities for the existence of coincidence points and fixed points," Journal of Applied Mathematics, vol. 2012, Article ID 196759, 12 pages, 2012.

[11] E. Karapinar and K. Sadarangani, "Fixed point theory for cyclic $(\varphi, \psi)$-contractions," Fixed Point Theory and Applications, vol. 2011, article 69, 2011.

[12] E. Karapınar, "Fixed point theory for cyclic weak $\phi$ contraction," Applied Mathematics Letters, vol. 24, no. 6, pp. 822-825, 2011.

[13] E. Karapınar and I. S. Yuce, "Fixed point theory for cyclic generalized weak $\phi$-contraction on partial metric spaces," Abstract and Applied Analysis, vol. 2012, Article ID 491542, 12 pages, 2012.

[14] B. E. Rhoades, "Some theorems on weakly contractive maps," Nonlinear Analysis, vol. 47, no. 4, pp. 2683-2693, 2001.

[15] B. Djafari Rouhani and S. Moradi, "Common fixed point of multivalued generalized $\varphi$-weak contractive mappings," Fixed Point Theory and Applications, Article ID 708984, 201013 pages, 2010.

[16] Q. Zhang and Y. Song, "Fixed point theory for generalized $\phi$ weak contractions," Applied Mathematics Letters, vol. 22, no. 1, pp. 75-78, 2009.

[17] L. B. Ćirić, N. Cakić, M. Rajović, and J. S. Ume, "Monotone generalized nonlinear contractions in partially ordered metric spaces," Fixed Point Theory and Applications, vol. 2008, Article ID 131294, 11 pages, 2008.

[18] T. G. Bhaskar and V. Lakshmikantham, "Fixed point theorems in partially ordered metric spaces and applications," Nonlinear Analysis: Theory, Methods \& Applications A, vol. 65, no. 7, pp. 1379-1393, 2006.

[19] J. Harjani, B. López, and K. Sadarangani, "Fixed point theorems for weakly $C$-contractive mappings in ordered metric spaces," Computers \& Mathematics with Applications, vol. 61, no. 4, pp. 790-796, 2011.

[20] J. Harjani, B. López, and K. Sadarangani, "A fixed point theorem for mappings satisfying a contractive condition of rational type on a partially ordered metric space," Abstract and Applied Analysis, vol. 2010, Article ID 190701, 8 pages, 2010.

[21] J. J. Nieto and R. Rodríguez-López, "Contractive mapping theorems in partially ordered sets and applications to ordinary differential equations," Order, vol. 22, no. 3, pp. 223-239, 2005.

[22] A. C. M. Ran and M. C. B. Reurings, "A fixed point theorem in partially ordered sets and some applications to matrix equations," Proceedings of the American Mathematical Society, vol. 132, no. 5, pp. 1435-1443, 2004.

[23] B. S. Choudhury and A. Kundu, " $(\psi, \alpha, \beta)$-weak contractions in partially ordered metric spaces," Applied Mathematics Letters, vol. 25, no. 1, pp. 6-10, 2012. 


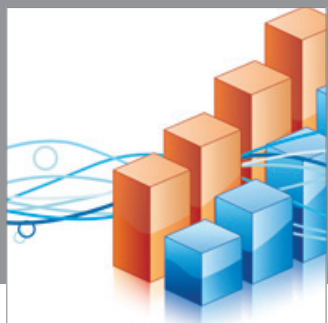

Advances in

Operations Research

mansans

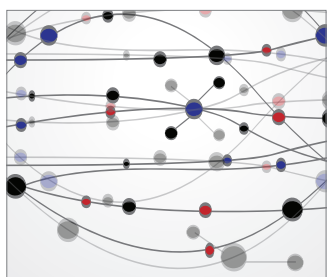

The Scientific World Journal
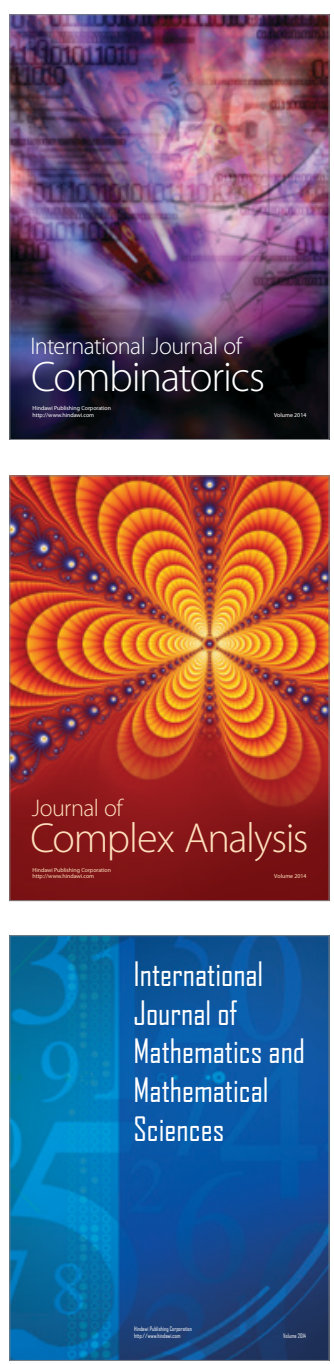
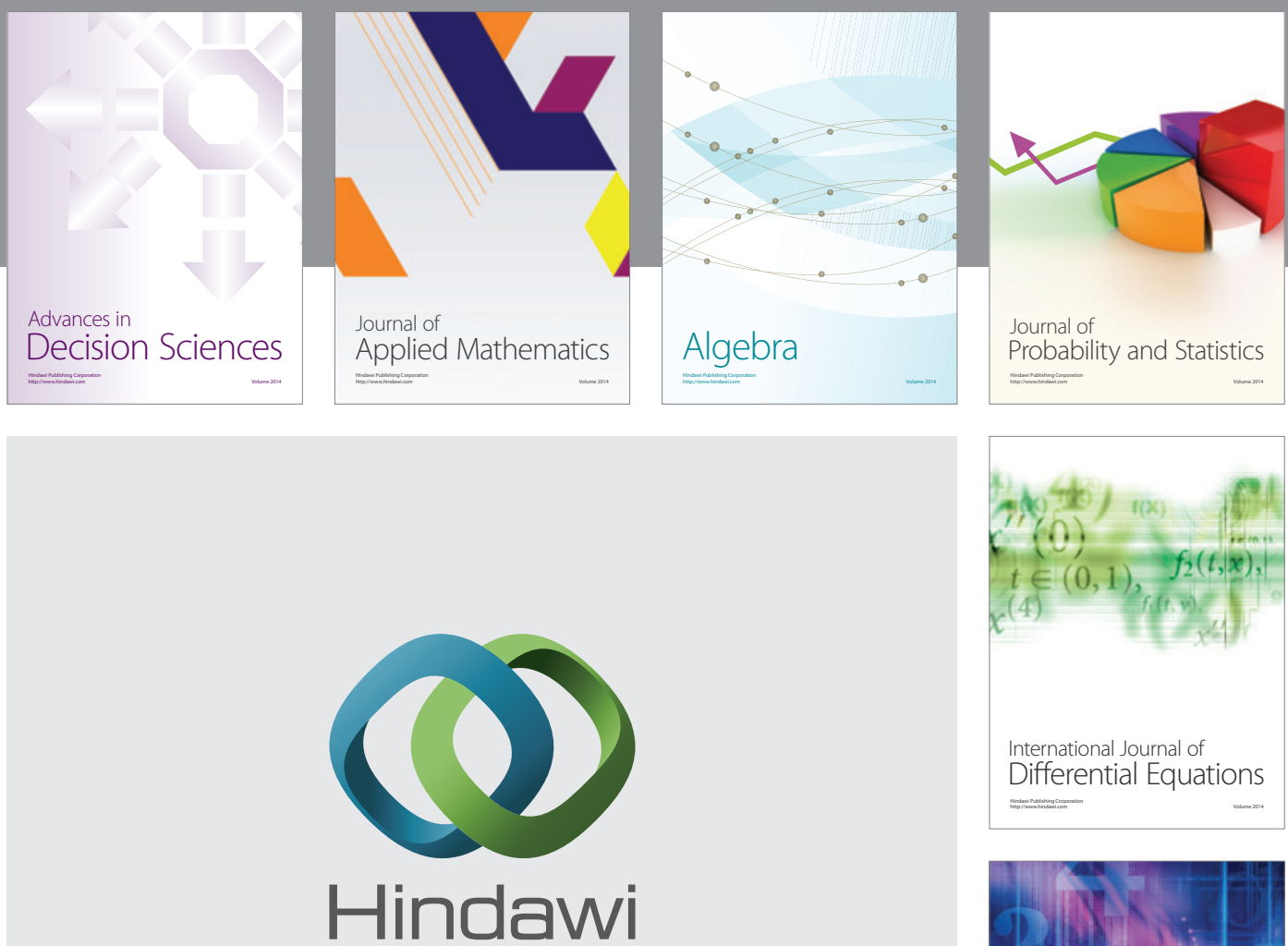

Submit your manuscripts at http://www.hindawi.com
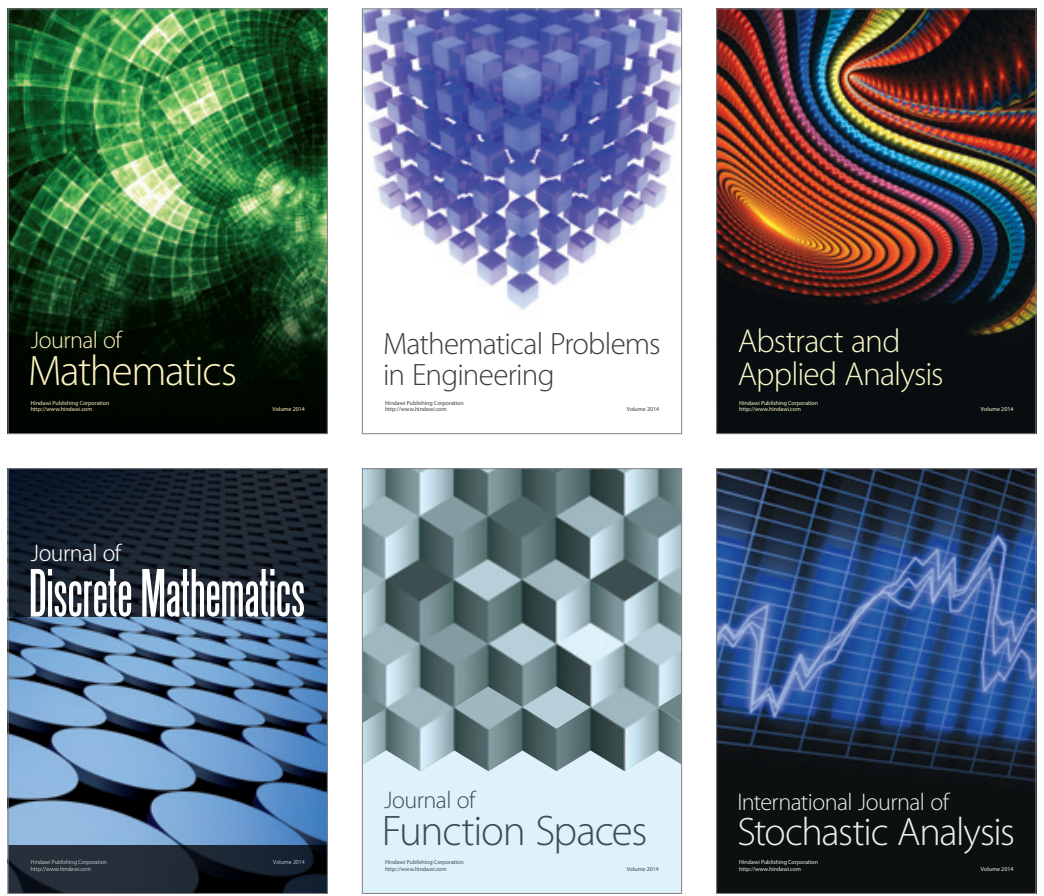

Journal of

Function Spaces

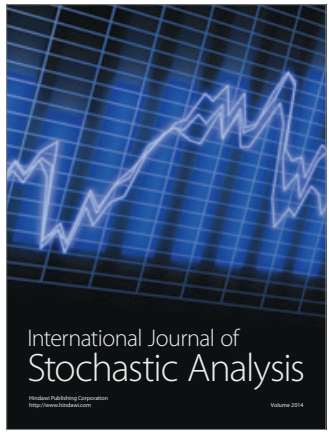

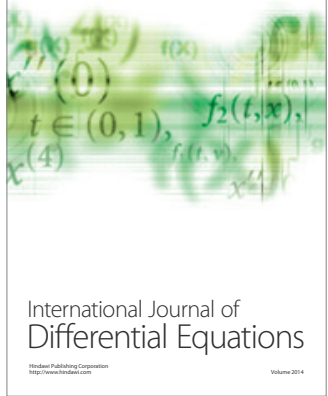
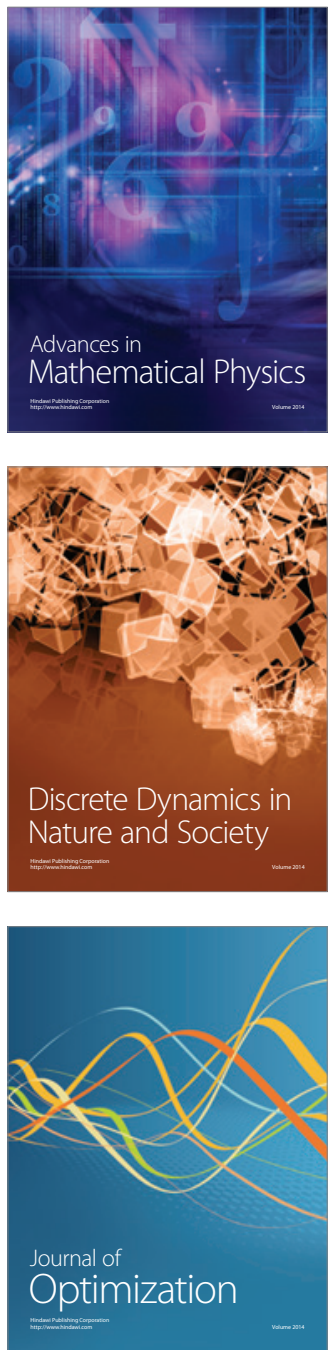